\title{
Successful Management of Acute Liver Failure Patients Waiting for Liver Transplantation by On-Line Hemodiafiltration with an Arteriovenous Fistula
}

\author{
Yuki Haga $^{a}$ Shin Yasui ${ }^{a}$ Tatsuo Kanda $^{a}$ Noriyuki Hattori ${ }^{b}$ \\ Toru Wakamatsu ${ }^{a}$ Masato Nakamura ${ }^{a}$ Reina Sasaki ${ }^{a}$ Shuang $\mathrm{Wu}^{\mathrm{a}}$ \\ Shingo Nakamoto ${ }^{a}$ Makoto Arai ${ }^{a}$ Hitoshi Maruyama ${ }^{a}$ \\ Masayuki Ohtsuka $^{c}$ Shigeto Oda ${ }^{\mathrm{b}}$ Masaru Miyazaki $^{\mathrm{c}}$ \\ Osamu Yokosuka ${ }^{a}$ \\ ${ }^{a}$ Department of Gastroenterology and Nephrology, Chiba University Graduate School of \\ Medicine, Chiba, Japan; ${ }^{b}$ Department of Emergency and Critical Care Medicine, Chiba \\ University, Graduate School of Medicine, and Department of Artificial Kidney, Chiba \\ University Hospital, Chiba, Japan; 'Department of General Surgery, Chiba University \\ Graduate School of Medicine, Chiba, Japan
}

\section{Keywords}

Acute liver failure $\cdot$ Infection $\cdot$ On-line hemodiafiltration

\begin{abstract}
On-line hemodiafiltration (OLHDF) is one of the treatment options in the management of acute liver failure (ALF) in Japan. It is essential to avoid infection in the management of ALF. In fact, infection is one of the prognostic factors in ALF. In this report, we present a middleaged Japanese man with ALF associated with benzbromarone use. He was successfully managed without infection until liver transplantation by creating an arteriovenous fistula for OLHDF. Utilizing an arteriovenous fistula for OLHDF, rather than inserting a vascular access catheter, is a beneficial option to avoid infectious diseases in the management of ALF.
\end{abstract}




\section{Introduction}

Acute liver failure (ALF) is a critical condition that can occasionally lead to death. Liver transplantation is an essential treatment option for ALF. Ho et al. [1] have reported that infectious diseases, alcohol abuse, and malignancy are several risk factors associated with poor prognosis in ALF patients. Clinicians need to pay special attention to the management of these risk factors.

On-line hemodiafiltration (OLHDF) uses a large amount of sterile dialysate as a substitution fluid and helps patients with ALF to achieve restoration of consciousness [2]. One of the advantages of OLHDF is that it removes ammonia, which could cause disturbances of consciousness in ALF patients. Occasionally, central venous catheters and bloodstream infection occur during HDF treatment. OLHDF is one of the most effective artificial liver support devices [2] in the treatment of ALF, and managing OLHDF without infections is preferable. In Japan as well as the USA, organ shortage is one of the problems in the field of liver transplantation [3]. Even patients with ALF should wait for a proper liver donor for deceased donor liver transplantation or living donor liver transplantation.

We report a patient with ALF associated with benzbromarone use who received OLHDF via an arteriovenous fistula to avoid infectious complications, and he was successfully rescued by liver transplantation.

\section{Case Report}

A 59-year-old Japanese man who had liver dysfunction for over 1 year was referred to the former hospital with fatigue and jaundice. Prior to developing liver dysfunction, he had been diagnosed with hyperuricemia, hypertension, and dyslipidemia. Benzbromarone $50 \mathrm{mg}$ daily, benidipine $4 \mathrm{mg}$ daily, and pravastatin $5 \mathrm{mg}$ daily were all prescribed. He also drank alcohol ( $\sim 60 \mathrm{~g}$ daily). After he had been diagnosed with liver dysfunction, ursodeoxycholic acid $400 \mathrm{mg}$ daily was prescribed. The laboratory examinations on admission to the former hospital showed the following values: total bilirubin, $8.1 \mathrm{mg} / \mathrm{dl}$; aspartate transaminase (AST), 1,457 IU/l; alanine transaminase (ALT), 1,696 IU/l; prothrombin time (PT), 69\%, and PT international normalized ratio (PT-INR), 1.33. Eight days after admission to the former hospital, the laboratory examinations showed the following values: total bilirubin level, 21.6 $\mathrm{mg} / \mathrm{dl} ;$ AST, $340 \mathrm{IU} / \mathrm{l} ;$ ALT, $529 \mathrm{IU} / \mathrm{l} ; \mathrm{PT}, 38 \%$, and PT-INR, 1.82. Although he had received conservative treatment, disorientation, drowsiness, and incontinence appeared 14 days after his prior hospitalization, and he was diagnosed as having ALF with grade 2 hepatic encephalopathy [3].

The patient was transferred to the Chiba University Hospital for treatment of the ALF. On admission, his body height and weight were $1.63 \mathrm{~m}$ and $60.2 \mathrm{~kg}$, respectively. On physical examination, deep jaundice, abdominal distension, and leg edema were observed. His liver and spleen were not palpable. Flapping tremor and disorientation were also detected.

The patient's laboratory data on this admission are shown in table 1. The serologic and virologic markers were negative. Autoimmune hepatitis was also ruled out [4]. Based on his medical history, we suspected that the benzbromarone was responsible for his hepatic injury $[5,6]$. CT imaging demonstrated heterogeneous hypoattentuation and atrophy of the liver with massive ascites (fig. 1). The Model for End-Stage Liver Disease (MELD) score of the 


\section{Case Reports in \\ Gastroenterology}

Case Rep Gastroenterol 2016;10:139-145 $10.1159 / 000445186$

(c) 2016 The Author(s). Published by S. Karger AG, Basel www.karger.com/crg

Haga et al.: Successful Management of Acute Liver Failure Patients Waiting for Live Transplantation by On-Line Hemodiafiltration with an Arteriovenous Fistula

patient was 24 [7]. He fulfilled a number of the criteria for liver transplantation. He was registered as a potential liver recipient, and we continued medical treatment. Until liver transplantation, intermittent OLHDF was performed to improve the disturbances in his level of consciousness. Surgical construction of an arteriovenous fistula was performed in the right forearm 12 days after admission to our unit. After evaluating the condition of his blood vessels, the fistula was constructed in the right forearm. The deceased donor liver transplantation was successfully performed without any infectious complications 53 days after admission to our unit. The volume of his liver was $730 \mathrm{~g}$, and histology of the liver revealed submassive necrosis in the right lobe and massive necrosis in the left lobe (fig. 2). There was no evidence of liver cirrhosis, supporting the diagnosis of ALF rather than acute-on-chronic liver failure [8]. During his hospitalization, no symptoms of infectious complications were observed (fig. 3). He remains well 1.5 years following transplantation. The fistula in his right forearm was closed 1 month after the liver transplantation.

\section{Discussion}

The clinical course of ALF is associated with rapidly progressive multiorgan failure and devastating complications such as encephalopathy and coagulopathy [4]. The present case had hepatic encephalopathy and coagulopathy. On admission to our hospital, this patient had grade 2 hepatic encephalopathy. Hemodiafiltration was essential to maintain the patient's level of consciousness [9]. He did not slip into coma.

On the other hand, sepsis is one of the poor prognostic factors for ALF [1]. Fujiwara et al. [10] reported that bacterial bloodstream infection was found in 35\% of cases with infectious complications in autoimmune ALF [10]. Infection is also an important prognostic factor for morbidity and mortality in hemodialysis and OLHDF patients with ALF [11]. Vascular accessrelated infection occurs frequently, and patients with arteriovenous fistulas for hemodialysis are at lower risk of death and infections when compared to patients with catheters [12]. In addition, Moura et al. [13] reported that patients who have arteriovenous fistulas for vascular access have higher health-related quality of life scores when compared to patients using central venous catheters. The patient in this report was initially admitted to the intensive care unit in our hospital. After he received an arteriovenous fistula, he was able to walk and perform rehabilitation training in a general patient room.

Our patient successfully avoided the risk of infectious diseases by having an arteriovenous fistula created in the right forearm for dialysis. His level of consciousness was maintained by intermittent rather than continuous OLHDF, and this might also have been beneficial to avoid other infections. There have been several reports that benzbromarone is occasionally associated with ALF $[14,15]$. When prescribing benzbromarone, clinicians should pay attention to the possibility of liver dysfunction. There may be no evidence to support this assumption, and not all patients transplanted for ALF who require temporary renal support via a dialysis catheter develop infections.

In conclusion, forming an arteriovenous fistula for dialysis may be a beneficial option in the management of ALF, although the excellent outcome in our patient was most likely related to the excellent care and surgical technique of the transplant team. 


\section{Case Reports in \\ Gastroenterology}

\begin{tabular}{l|l}
\hline $10.1159 / 000445186$ & $\begin{array}{l}\text { (c) } 2016 \text { The Author(s). Published by S. Karger AG, Basel } \\
\text { www.karger.com/crg }\end{array}$ \\
\hline
\end{tabular}

Haga et al.: Successful Management of Acute Liver Failure Patients Waiting for Live Transplantation by On-Line Hemodiafiltration with an Arteriovenous Fistula

\section{Statement of Ethics}

There are no ethical conflicts to declare.

\section{Disclosure Statement}

The authors declare that they have no competing interests.

\section{References}

1 Ho CM, Lee CH, Wang JY, Lee PH, Lai HS, Hu RH: Nationwide longitudinal analysis of acute liver failure in Taiwan. Medicine (Baltimore) 2014;93:e35.

-2 Fujiwara K, Oda S, Abe R, Yokosuka 0: On-line hemodiafiltration or high-flow continuous hemodiafiltration is one of the most effective artificial liver support devices for acute liver failure in Japan. J Hepatobiliary Pancreat Sci 2015;22:246-247.

-3 Kanda T, Yokosuka O, Ehata T, Maru Y, Imazeki F, Saisho H, Shiratori Y, Omata M: Detection of GBV-C RNA in patients with non-A-E fulminant hepatitis by reverse-transcription polymerase chain reaction. Hepatology 1997;25:1261-1265.

-4 Czaja AJ: Comparability of probable and definite autoimmune hepatitis by international diagnostic scoring criteria. Gastroenterology 2011;140:1472-1480.

5 Watanabe M, Shibuya A: Validity study of a new diagnostic scale for drug-induced liver injury in Japan comparison with two previous scales. Hepatol Res 2004;30:148-154.

-6 Shirakawa M, Sekine S, Tanaka A, Horie T, Ito K: Metabolic activation of hepatotoxic drug (benzbromarone) induced mitochondrial membrane permeability transition. Toxicol Appl Pharmacol 2015;288:12-18.

7 Kamath PS, Wiesner RH, Malinchoc M, Kremers W, Therneau TM, Kosberg CL, D'Amico G, Dickson ER, Kim WR: A model to predict survival in patients with end-stage liver disease. Hepatology 2001;33:464470.

-8 Sarin SK, Kedarisetty CK, Abbas Z, et al; APASL ACLF Working Party: Acute-on-chronic liver failure: consensus recommendations of the Asian Pacific Association for the Study of the Liver (APASL) 2014 Hepatol Int 2014;8:453-471.

-9 Slack AJ, Auzinger G, Willars C, Dew T, Musto R, Corsilli D, Sherwood R, Wendon JA, Bernal W: Ammonia clearance with haemofiltration in adults with liver disease. Liver Int 2014;34:42-48.

10 Fujiwara K, Yasui S, Yonemitsu Y, Arai M, Kanda T, Fukuda Y, Nakano M, Oda S, Yokosuka O: Analysis of infectious complications and timing for emergency liver transplantation in autoimmune acute liver failure. J Hepatobiliary Pancreat Sci 2016;23:212-219.

11 den Hoedt CH, Grooteman MP, Bots ML, Blankestijn PJ, van der Tweel I, van der Weerd NC, Penne EL, Mazairac AH, Levesque R, ter Wee PM, Nubé MJ, van den Dorpel MA; CONTRAST Investigators: The effect of online hemodiafiltration on infections: results from the CONvective TRAnsport STudy. PLoS One 2015;10:e135908.

12 Ravani P, Palmer SC, Oliver MJ, Quinn RR, MacRae JM, Tai DJ, Pannu NI, Thomas C, Hemmelgarn BR, Craig JC, Manns B, Tonelli M, Strippoli GF, James MT: Associations between hemodialysis access type and clinical outcomes: a systematic review. J Am Soc Nephrol 2013;24:465-473.

13 Moura A, Madureira J, Alija P, Fernandes JC, Oliveira JG, Lopez M, Filgueiras M, Amado L, Sameiro-Faria M, Miranda V, Vieira M, Santos-Silva A, Costa E: Type of vascular access and location in online hemodiafiltration and its association with patient's perception of health-related quality of life. J Vasc Access 2014;15:175-182.

-14 Arai M, Yokosuka O, Fujiwara K, Kojima H, Kanda T, Hirasawa H, Saisho H: Fulminant hepatic failure associated with benzbromarone treatment: a case report. J Gastroenterol Hepatol 2002;17:625-626.

15 Wagayama H, Shiraki K, Sugimoto K, Fujikawa K, Shimizu A, Takase K, Nakano T, Tameda Y: Fatal fulminant hepatic failure associated with benzbromarone. J Hepatol 2000;32:874. 


\section{Case Reports in Gastroenterology}
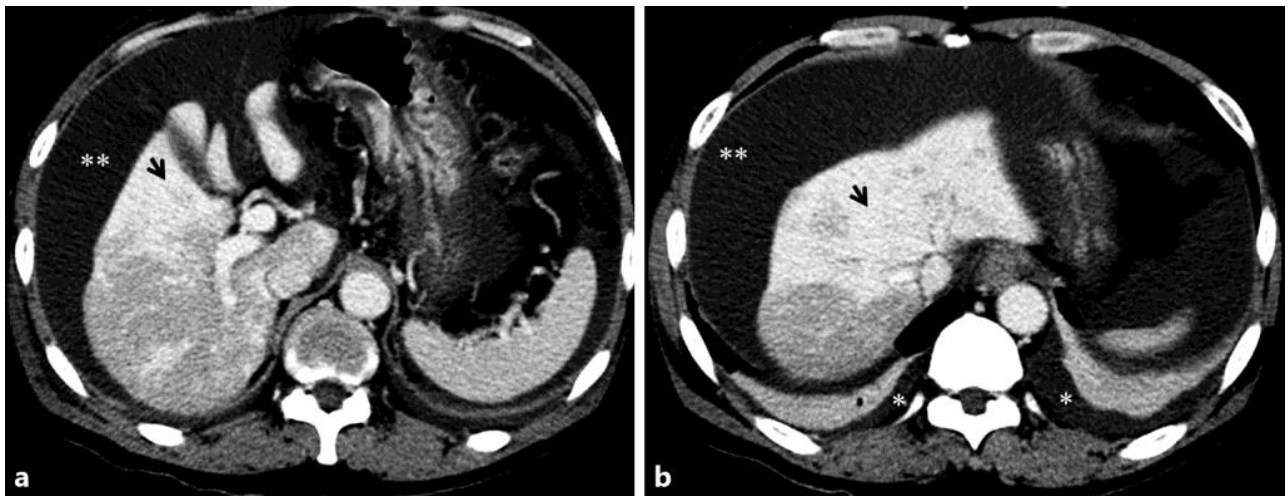

Fig. 1. Contrast-enhanced CT revealed necrotic changes (arrows) and atrophy of the liver with massive ascites $\left(\mathbf{a}, \mathbf{b} ;{ }^{* *}\right)$ and bilateral pleural effusions $\left(\mathbf{b} ;{ }^{*}\right)$.
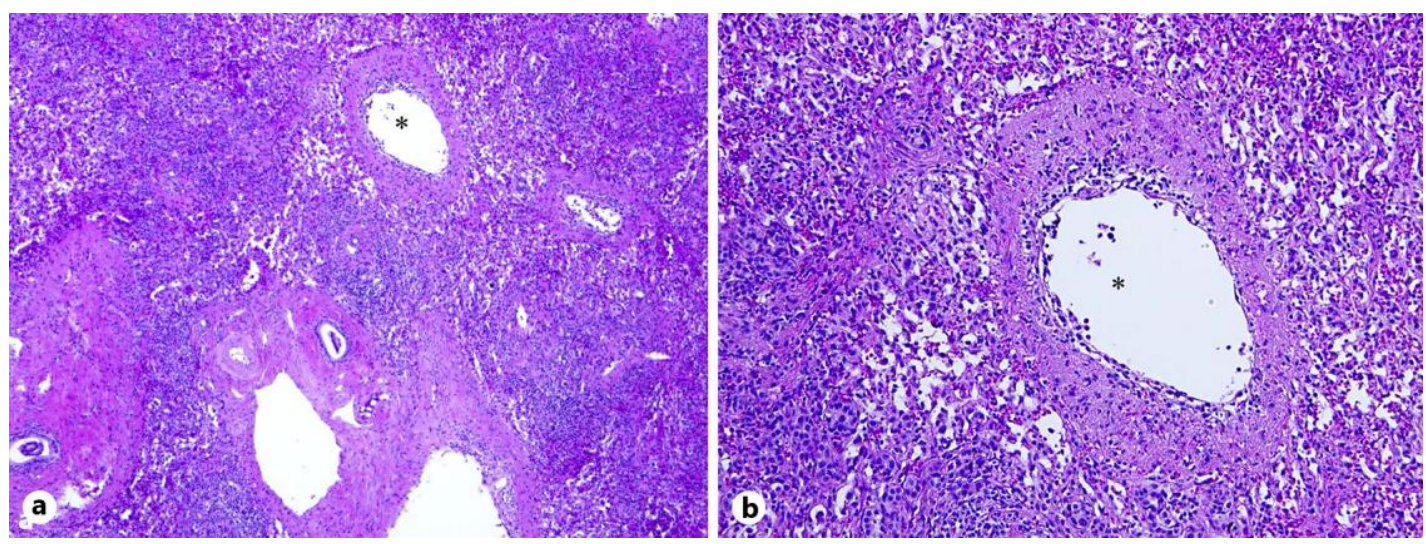

Fig. 2. A histological examination was conducted on the explanted liver. The microscopic findings revealed massive hemorrhagic necrosis. ${ }^{*}$ Central veins of the liver. HE. $\mathbf{a} \times 40 . \mathbf{b} \times 200$. 


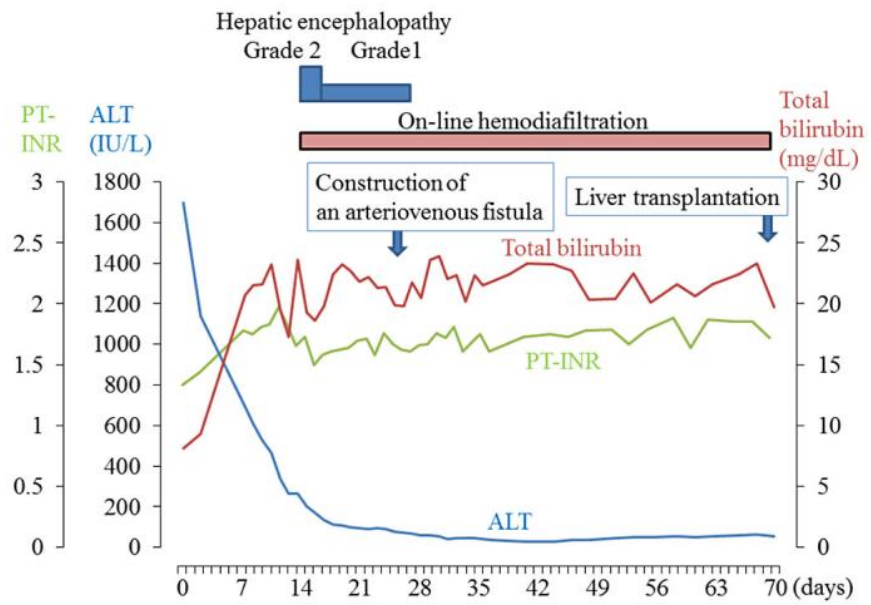

Days from the admission to the first hospital

Fig. 3. Chart showing the course of ALT, PT-INR, and total bilirubin from first admission until liver transplantation. Total bilirubin level plateaued with medical treatment until liver transplantation. 
Haga et al: Successful Management of Acute Liver Failure Patients Waiting for Live Transplantation by On-Line Hemodiafiltration with an Arteriovenous Fistula

Table 1. Laboratory data on admission to our hospital

\begin{tabular}{|c|c|c|c|c|c|}
\hline Parameter & Result & Normal value & Parameter & Result & Normal value \\
\hline White blood cells, $\mathrm{n} / \mu \mathrm{l}$ & 17,000 & $4,000-9,000$ & HBsAg & - & - \\
\hline Eosinophils, \% & 0 & $1.0-5.0$ & IgM-anti-HBc & - & - \\
\hline Red blood cells, $\mathrm{n} / \mu \mathrm{l}$ & $482 \times 10^{4}$ & $410-530$ & HBV DNA & - & - \\
\hline Hemoglobin, g/dl & 15.7 & $14.0-17.0$ & IgM-anti-HA & - & - \\
\hline Platelets, $\mathrm{n} / \mu \mathrm{l}$ & $9.5 \times 10^{4}$ & $15.0-35.0$ & anti-HCV & - & - \\
\hline $\mathrm{PT}, \%$ & 32 & $81-121$ & HCV RNA & - & - \\
\hline PT-INR & 1.65 & $0.86-1.06$ & IgA-anti-HEV & - & - \\
\hline Total cholesterol, mg/dl & 140 & $125-219$ & anti-HIV & - & - \\
\hline Total protein, g/dl & 5.8 & $6.5-8.2$ & anti-HTLV-I & - & - \\
\hline Albumin, g/dl & 2.9 & $3.9-5.1$ & $\mathrm{IgG}, \mathrm{mg} / \mathrm{dl}$ & 1,312 & $870-1,700$ \\
\hline AST, IU/l & 68 & $13-33$ & $\operatorname{IgA}, \mathrm{mg} / \mathrm{dl}$ & 253 & $110-410$ \\
\hline ALT, IU/l & 256 & $8-42$ & $\mathrm{IgM}, \mathrm{mg} / \mathrm{dl}$ & 42 & $35-220$ \\
\hline LDH, IU/l & 399 & $119-229$ & $\mathrm{HGF}, \mathrm{ng} / \mathrm{ml}$ & 1.58 & $<0.4$ \\
\hline ALP, IU/l & 690 & $115-359$ & ANA & - & - \\
\hline$\gamma$-GTP, IU/l & 138 & $10-47$ & ASMA & - & - \\
\hline Total bilirubin, mg/dl & 23.6 & $0.2-1.2$ & AMA M2 & - & - \\
\hline Direct bilirubin, mg/dl & 16.8 & $0-0.2$ & Ceruloplasmin, $\mu \mathrm{g} / \mathrm{dl}$ & 102 & $21-37$ \\
\hline Blood urea nitrogen, $\mathrm{mg} / \mathrm{dl}$ & 16 & $8-20$ & $\mathrm{AFP}, \mathrm{ng} / \mathrm{ml}$ & 12.5 & $<8.0$ \\
\hline Creatinine, mg/dl & 0.63 & $0.61-1.04$ & Ammonia, $\mu \mathrm{g} / \mathrm{dl}$ & 81 & $12-66$ \\
\hline Glucose, mg/dl & 214 & $70-119$ & $\mathrm{TSH}, \mu \mathrm{IU} / \mathrm{ml}$ & 0.082 & $0.350-4.940$ \\
\hline $\mathrm{CRP}, \mathrm{mg} / \mathrm{dl}$ & 0.3 & $0.0-0.2$ & $\mathrm{fT}_{3}, \mathrm{pg} / \mathrm{ml}$ & 1.20 & $1.71-3.71$ \\
\hline $\mathrm{ESR}, \mathrm{mm} / \mathrm{h}$ & 1 & $2-10$ & $\mathrm{fT}_{4}, \mathrm{ng} / \mathrm{dl}$ & 0.98 & $0.70-1.48$ \\
\hline
\end{tabular}

AFP $=\alpha$-Fetoprotein; ALP = alkaline phosphatase; AMA M2 = anti-mitochondrial antibody M2; ANA = anti-nuclear antibody; anti-HCV = anti-hepatitis C virus antibody; anti-HIV = anti-human immunodeficiency virus antibody; anti-HTLV-I = antihuman T-cell leukemia virus; ASMA = anti-smooth muscle antibody; CRP = C-reactive protein; ESR = erythrocyte sedimentation rate; $\mathrm{fT}_{3}=$ free triiodothyronine; $\mathrm{fT}_{4}=$ free thyroxine; $\gamma$-GTP $=\gamma$-glutamyltransferase; $\mathrm{HBsAg}=$ hepatitis $\mathrm{B}$ surface antigen; HBV DNA = hepatitis B virus DNA; HCV RNA = hepatitis C virus RNA; HGF = hepatic growth factor; IgA = immunoglobulin A; IgA-anti-HEV = anti-hepatitis E virus IgA antibody; IgG = immunoglobulin G; IgM = immunoglobulin M; IgM-anti-HA = antihepatitis A IgM antibody; IgM-anti-HBc = anti-HBV core IgM antibody; LDH = lactate dehydrogenase; TSH = thyroidstimulating hormone; - = negative. 